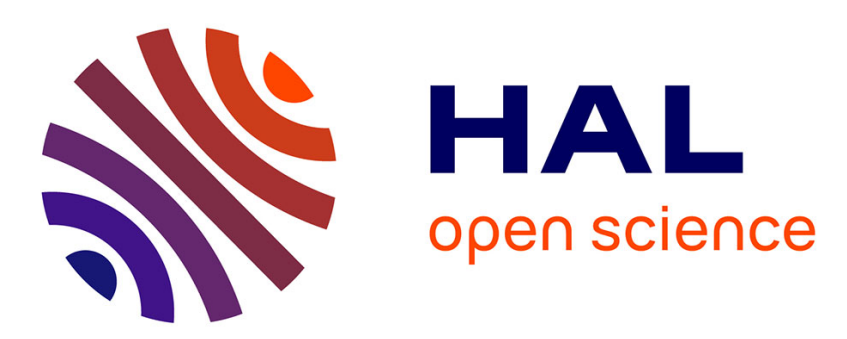

\title{
Behaviour of human dental pulp stem cell in high glucose condition: impact on proliferation and osteogenic differentiation
}

\author{
Charlene Kichenbrand, Laurent Grossin, Patrick Menu, Vanessa Moby
}

\section{To cite this version:}

Charlene Kichenbrand, Laurent Grossin, Patrick Menu, Vanessa Moby. Behaviour of human dental pulp stem cell in high glucose condition: impact on proliferation and osteogenic differentiation. Archives of Oral Biology, 2020, 118, pp.104859. 10.1016/j.archoralbio.2020.104859 . hal-02943979

\author{
HAL Id: hal-02943979 \\ https://hal.science/hal-02943979
}

Submitted on 4 Jan 2021

HAL is a multi-disciplinary open access archive for the deposit and dissemination of scientific research documents, whether they are published or not. The documents may come from teaching and research institutions in France or abroad, or from public or private research centers.
L'archive ouverte pluridisciplinaire HAL, est destinée au dépôt et à la diffusion de documents scientifiques de niveau recherche, publiés ou non, émanant des établissements d'enseignement et de recherche français ou étrangers, des laboratoires publics ou privés. 
Behaviour of human dental pulp stem cell in high glucose condition: impact on proliferation and osteogenic differentiation.

Charlene Kichenbrand 1,2,3 (charlene.kichenbrand@univ-lorraine.fr), Laurent Grossin 1 (laurent.grossin@univ-lorraine.fr), Patrick Menu 1,4 (patrick.menu@univ-lorraine.fr), Vanessa Moby 1,2,3,* (vanessa.moby@univ-lorraine.fr)

${ }^{1}$ Université de Lorraine, CNRS, UMR 7365, IMoPA, F-54000 Nancy, France.

${ }^{2}$ CHRU Nancy, Service Odontologie, F-54000 Nancy, France.

${ }^{3}$ Faculté d'Odontologie, Université de Lorraine, F-54000 Nancy, France.

${ }^{4}$ Faculté de Pharmacie, Université de Lorraine, F-54000 Nancy, France.

*Corresponding author: Vanessa Moby, PhD, DDS, Associate Professor/ Hospital Practitioner, Université de Lorraine, CNRS, UMR 7365, Ingénierie Moléculaire et Physiopathologie Articulaire (IMoPA), Biopôle de l'Université de Lorraine, Campus BiologieSanté, 9 Avenue de la Forêt de Haye, BP20199, Vandœuvre-lès-Nancy, F-54505, France Cedex. E-mail: vanessa.moby@univ-lorraine.fr

Tel: +33372746581

Fax: +33372746545

\section{Running title: Dental stem cells and glucose condition}

\footnotetext{
Abbreviations: AR (Alizarin red), BM (bone marrow), DMEM (Dulbecco's modified Eagle's medium), DMSO (Dimethysulfoxide), DPSCs (dental pulp stem cells), FBS (fetal bovine serum), HG (high glucose), LG (low glucose), MSCs (mesenchymal stromal/stem cells), MTT (3-(4,5-dimethylthiazol-2-yl)-2,5-diphenyltetrazolium bromide), PBS (Phosphate Buffered Saline), PDLSCs (periodontal ligament stem cells), SCAPS (stem cells from the apical papilla), SHEDs (stem cells from human exfoliated deciduous teeth),
} 


\section{Abstract}

Objective: The aim of this study is to investigate the changes of human dental pulp stem cell (hDPSC) viability, proliferation and osteogenic differentiation in high glucose condition.

Design: After 21 days of culture in low $(5.5 \mathrm{mM})$ and high $(20 \mathrm{mM})$ glucose medium, hDPSC viability and proliferation were assessed with respectively the 3-(4,5-dimethylthiazol-2-yl)-2,5diphenyltetrazolium bromide (MTT) and Hoechst assays.

To investigate the influence of glucose on osteogenic differentiation hDPSCs were cultured for 28 days in low or high glucose medium with osteoinductive cocktail. Mineralization was examined by alizarin red staining/quantification and the expression of osteogenic-related genes [Runt-related transcription factor 2 (RUNX2), Osteocalcin (OCN), Collagen 1A1 (COL1A1)] analyzed by RT-qPCR.

Results: We observed no significant difference $(p>0.05)$ on hDPSC proliferation or cell viability between low or high glucose groups. We did not highlight a significant difference after alizarin red staining and quantification between hDPSCs cultured with high or low glucose concentration in the culture medium. In the same manner, high glucose concentration did not appear to modify osteogenic gene expression: there was no significant difference in osteogenicrelated gene expression between high or low glucose groups.

Conclusion: Proliferation, viability, and osteogenic differentiation of hDPSCs were not changed by high glucose environment.

Key words: dental pulp stem cells; cell proliferation; osteogenic differentiation; glucose; bone tissue engineering 


\section{Introduction}

The main purpose in tissue engineering is to reconstruct native tissue by associating progenitor or mesenchymal stromal/stem cells (MSCs) and a suitable scaffold. Some studies have shown that MSCs represent attractive cells for bone tissue engineering (Le Blanc \& Pittenger, 2005; Neuss et al, 2008; Zhang et al, 2009). MSCs can be obtained from different sources, but bone marrow MSCs (BM-MSCs) are widely considered as a gold standard (Polymeri, Giannobile \& Kaigler, 2016). BM-MSCs have been successfully used to repair critical-size bone defects in vivo, and their use is well-documented for years (Quarto et al, 2001; Wexler et al, 2003). However, BM-MSCs present some disadvantages (harvested by invasive and painful surgical procedure), and other sources of MSCs have been considered.

Among the wide family of MSCs of human origin such as adipose tissue-derived MSCs or umbilical cord-derived MSCs, dental pulp stem cells (DPSCs) are MSCs that originate from the cranial neural crest and reside within the perivascular niche of the dental pulp. DPSCs were first isolated and described in the early 2000s (Gronthos, Mankani, Brahim, Robey \& Shi, 2000) and represent a valuable non-invasive source of MSCs for tissue engineering or cell therapies (Kichenbrand, Velot, Menu \& Moby, 2019). Interestingly, they are easily accessible with limited morbidity in the operation site and are often obtained from tooth extraction for orthodontic reasons. DPSCs have immune privilege and anti-inflammatory properties (Kichenbrand, Velot, Menu \& Moby, 2019), display high growth rate (Alge et al, 2010), multilineage differentiation ability (Zhang, Walboomers, Shi, Fan, \& Jansen., 2006) and so can regenerate various tissues. The osteogenic potential of DPSCs was described previously (Cha et al, 2015; Chamieh et al, 2016; Giuliani et al, 2013; Laino et al, 2006 ${ }^{\text {; }}$ Ling et al, 2015; Wongsupa, Nuntanaranont, Kamolmattayakul, \& Thuaksuban, 2017). DPSCs are capable of differentiating into osteoblasts in vitro after an induction by dexamethasone, ascorbic acid and 
$\beta$-glycerophosphate supplementation (Cha et al, 2015; Laino et al, 2006 ${ }^{\text {b }}$. They are able to form woven bone in vitro and in vivo by secreting abundant extracellular matrix (Laino et al, $2006^{\mathrm{b}}$ ). This osteogenic potential of DPSCs has been demonstrated in rat models (Chamieh et al, 2016; Ling et al, 2015), rabbit models (Wongsupa, Nuntanaranont, Kamolmattayakul \& Thuaksuban, 2017) and in human studies to repair jaw defects (Giuliani et al, 2013). This osteogenic potential is therefore of major interest, notably in the field of oral and maxillofacial defect therapeutics.

Despite the considerable promise offered by MSCs to repair damaged bone tissue, bone constructs in human trials often present modest or short-lived benefits. The key to overcoming the limits after transplantation may lie in better understanding the influence of biochemical microenvironment and local factors such as hypoxia or glucose concentration. Glucose plays a major role in modifying cells proliferation and differentiation in vitro (Stolzing, Coleman \& Scutt, 2006; Weil, Abarbanell, Herrmann, Wang \& Meldrum, 2009). Pathological conditions such as diabetes mellitus are associated with hyperglycemic environment that impacts osteoblasts and bone formation (Kalaitzoglou, Popescu, Bunn, Fowlkes \& Thrailkill, 2016). Thus, diabetic patients are known to present an increased risk of delayed bone healing, that lead to major issues especially in the field of oral and maxillo-facial surgery (Jiao, Xiao \& Graves, 2015). Bone tissue engineering in those patients require using MSCs that can overcome high glucose conditions in order to improve the benefits of bone constructs. Elucidating the impact of glucose concentration on cells culture is essential to enhance cell survival and differentiation potential. In vitro, MSCs can be amplified and differentiated toward different cell lineages for regenerative therapies by applying culture media of different composition, notably various glucose concentrations (Saki, Jalalifar, Soleimani, Hajizamani, \& Rahim, 2013). The effects of glucose concentration have been investigated on several types of MSCs, including BM-MSCs (Elseberg et al, 2012; Li et al, 2007; Stolzing, Bauer \& Scutt, 2012; Wang et al, 2013; Zhang 
et al, 2017), adipose-derived mesenchymal stem cells (Liang et al, 2012), periodontal ligament stem cells (PDLSCs) (Kato et al, 2016; Seubbuk, Sritanaudomchai, Kasetsuwan \& Surarit, 2017), tendon-derived stem cells (Lin et al, 2017), embryonic stem cells (Yang, Shen, Reece, Chen \& Yang, 2016) or stem cells from the apical papilla (SCAPs) (Wang, Wang, Lu \& Yu, 2019). To date, existing studies on the influence of glucose on MSC proliferation and differentiation exhibited quite puzzling results and did not provide a clear answer to the exact influence of glucose.

Furthermore, only one work focused on the impact of glucose on DPSC functioning (Kanafi, Ramesh, Gupta \& Bhonde, 2013), and its repercussion on DPSC osteogenic differentiation has not yet been clearly studied.

Therefore, in this work, we aimed to investigate the changes of DPSC proliferation, viability and osteogenic differentiation in high glucose environment. We chose two glucose concentrations that corresponds to the routinely used culture medium $(5.5 \mathrm{mM}$ and $20 \mathrm{mM})$.

\section{Materials and methods}

\subsection{Isolation and culture of human DPSCs (hDPSCs)}

\subsubsection{Isolation of hDPSCs}

Impacted third molars were collected from healthy donors (aged 13-17 years) after receiving written informed consent from the patients and their parents, according to the amended Declaration of Helsinki and following a protocol approved by the French Ministry of Higher Education and Research (CELSORDINO: ID-RCB: 2017-A00860-53). Only teeth between Nolla developmental stages 5 (crown almost completed) and 7 (one third root completed) were collected. The explant method was used to isolate hDPSCs as described previously (Ducret et al, 2015; Hilkens et al, 2013). Briefly, dental pulps were gently extirpated from teeth and cut 
into small fragments. Explants were placed into 6-well plates in Dulbecco's modified Eagle's medium (DMEM) supplemented with 10\% fetal bovine serum (FBS).

\subsubsection{Culture of hDPSCs}

DPSCs migrated from the pulp explants were amplified $\left(5 \times 10^{3}\right.$ cells $\left./ \mathrm{cm}^{2}\right)$ in the same medium and maintained in a humidified atmosphere of $5 \% \mathrm{CO}_{2}$ at $37^{\circ} \mathrm{C}$ with a medium changes two times a week. They were either frozen after two passages or used to confirm the MSC phenotype by flow cytometry. Cells were negative for the hematopoietic surface markers CD34, CD45 and positive for CD73, CD 90 and CD105 (data not shown). Cells isolated from three different donors were used.

\subsection{Assessment of cell proliferation}

Post-thaw P3-DPSCs were plated in 6-well plates at conventional seeding density $\left(5 \times 10^{3}\right.$ cells $/ \mathrm{cm}^{2}$ ) and cultured for 21 days, in a humidified atmosphere of $5 \% \mathrm{CO} 2$ at $37^{\circ} \mathrm{C}$, shared in two groups: 1) low glucose DMEM (LG-DMEM) with a glucose concentration of $5.5 \mathrm{mM} ; 2$ ) high glucose DMEM (HG-DMEM) with a glucose concentration of $20 \mathrm{mM}$. Media were purchased from Gibco and supplemented with $10 \%$ FBS, $100 \mathrm{U} / \mathrm{mL}$ penicillin, $100 \mu \mathrm{g} / \mathrm{mL}$ streptomycin and $2.5 \mu \mathrm{g} / \mathrm{mL}$ amphotericin B (Sigma-Aldrich). The medium was changed every 3-4 days.

Cell proliferation was evaluated by measuring DNA concentration. This last was assessed using Hoechst 33342 fluorescent stain at days 1, 3, 7, 14 and 21. Cell amounts were determined by a fluorometric quantification of DNA using Hoechst assay. Cells were trypsinized (TypLE®, Gibco), centrifuged at $300 \mathrm{~g}$ during $10 \mathrm{~min}$ and diluted in Hoechst buffer, followed by three cycles of freezing $\left(-80{ }^{\circ} \mathrm{C}\right)$ and thawing $\left(37^{\circ} \mathrm{C}\right)$. After cell lysis, Hoechst 33342 fluorescent dye $(0.1 \mu \mathrm{g} / \mathrm{ml}$, Sigma-Aldrich, USA) was added. Sample supernatant $(200 \mu \mathrm{l})$ was taken off, and the fluorescence was measured at a wavelength of $350-461 \mathrm{~nm}$ with a Varioskan ${ }^{\mathrm{TM}} \mathrm{LUX}$ 
multimode microplate reader. A DNA standard curve was realized to determinate the DNA concentration in the samples. The DNA absorbances were used to normalize the cell viability.

\subsection{Evaluation of cell viability}

Cell viability was evaluated by analyzing the mitochondrial activities of the hDPSCs. The 3(4,5-dimethylthiazol-2-yl)-2,5-diphenyltetrazolium bromide (MTT) assay was used to quantitatively assess the number of viable hDPSCs grown in the two culture conditions (LGDMEM and HG-DMEM). Post-thaw P3-hDPSCs were seeded in 96-well plates at conventional seeding density $\left(5 \times 10^{3}\right.$ cells $\left./ \mathrm{cm}^{2}\right)$ in a humidified atmosphere of $5 \% \mathrm{CO}_{2}$ at $37^{\circ} \mathrm{C}$ and were cultured for $1,3,7,14$ and 21 days. The medium was changed every 3-4 days. The MTT solution was prepared by dissolving MTT in phosphate buffered saline (PBS), after which it was filtered and sterilized. After the predetermined time intervals (1, 3, 7,14 or 21 days), cells were incubated with $5 \mathrm{mg} / \mathrm{ml}$ MTT (Sigma) for 4 hours at $37{ }^{\circ} \mathrm{C}$. The MTT solution was discarded and the blue formazan crystals formed, representative of cell viability, were solubilized from the cells by incubation with dimethylsulfoxide (DMSO) for 5 minutes at $37^{\circ} \mathrm{C}$. Aliquots of the resulting solutions were transferred to new plates. The absorbance was measured at $540 \mathrm{~nm}$ using a Varioskan ${ }^{\mathrm{TM}}$ LUX multimode microplate reader. The MTT absorbance normalized by Hoechst absorbance was calculated for each sample.

\subsection{Osteogenic differentiation of hDPSCs}

To evaluate the effect of glucose concentration on osteoblast differentiation, hDPSCs were incubated in HG or LG osteogenic culture medium (DMEM supplemented with 10\% FBS, pyruvate, penicillin/streptomycin, amphotericin B and osteogenic cocktail dexamethasone (100 $\mathrm{nM})$, ascorbic acid $(50 \mu \mathrm{M}), \beta$-glycerophosphate $(10 \mathrm{mM}))$. hDPSCs at passage 3 were cultured for 28 days in 6-well plates at conventional seeding density $\left(5 \times 10^{3}\right.$ cells $\left./ \mathrm{cm}^{2}\right)$ and in a 
humidified atmosphere of $5 \% \mathrm{CO}_{2}$ at $37^{\circ} \mathrm{C}$. The medium was changed every $3-4$ days. We used as negative control DMEM without osteogenic differentiation cocktail.

\subsubsection{Alizarin red staining}

The formation of calcium nodules in osteogenic differentiated hDPSCs was assessed using alizarin red (AR) staining, according to Stanford (Stanford, Jacobson, Eanes, Lembke \& Midura, 1995). After culture under osteogenic-inducing conditions for 28 days in 6-well plates, hDPSCs were washed three times with PBS ( $\mathrm{pH} 7.4$ ), fixed with 4\% paraformaldehyde for 15 min, incubated with 2\% AR solution (Sigma-Aldrich) and finally rinsed three times with PBS. The calcium nodules were visualized under conventional microscopy (10× magnification). To quantify the mineralization, we extracted calcified nodules at low $\mathrm{pH}$ and neutralized with ammonium hydroxide, as previously described (Gregory, Gunn, Peister \& Prockop, 2004). Briefly, cultures were destained with acetic acid (10\%v/v) for 30 minutes at room temperature. The monolayer was scraped off, heated at $85^{\circ} \mathrm{C}$ for 10 minutes, cooled with ice for 5 minutes and centrifuged at $20,000 \mathrm{~g}$ for 15 minutes. Resulted supernatant was removed, and $\mathrm{pH}$ adjusted (4.1-4.5) with ammonium hydroxide.

The absorbance values at $405 \mathrm{~nm}$ were detected using a microplate reader, and AR staining concentrations were calculated according to its standard curve. Three independent experiments were performed in triplicates. We used as negative control DMEM without osteogenic differentiation cocktail.

2.4.2. RNA isolation and reverse transcription quantitative polymerase chain reaction $(R T-q P C R)$

To analyze osteogenic-related gene expression, total RNA was isolated at day 28 by adding Quiazol reagent (QIAzol®Lysis Reagent, Qiagen) and extracted from cultured hDPSCs using Direct-zol ${ }^{\text {тM }}$ RNA MiniPrep (Zymo Research). About 50 ng of total RNA were reverse 
transcribed into complementary deoxyribonucleic acid (cDNA) using the cDNA synthesis kit (iScript ${ }^{\mathrm{TM}}$ Reverse Transcription Supermix for RT-qPCR, Biorad). The RT-qPCR was performed by using iTaq ${ }^{\mathrm{TM}}$ Universal SYBER ${ }^{\circledR}$ Green Supermix (Biorad) and system StepOne Plus Apparatus (Real Time PCR System, Applied Biosystem, USA) to compare the expression of Runt-related transcription factor 2 (RUNX2), osteocalcin $(O C N)$ and collagen 1A1 (COL1A1) genes (Table 1) between cells cultured with different glucose concentrations.

Gene expression levels were obtained from cells of three different patients, cultured in triplicate. Gene expression levels were calculated by the comparative delta CT method $\left(2^{-\Delta c t}\right.$ formula) after being normalized to the CT value of the ribosomal protein housekeeping gene (RP29).

\subsection{Statistical analysis}

Data are expressed as mean \pm standard error or medians (alizarin red assay). Each experimentation has been made in triplicate and was repeated independently three times $(n=$ 3). Differences between groups were analyzed on ranks using Mann-Whitney and KruskalWallis (alizarin red assay) nonparametric tests (GraphPad Prism software (GraphPad Inc, CA, USA)). $P$ values lower than 0.05 were considered to be statistically significant.

\section{Results}

\subsection{Effects of high glucose concentration on cell proliferation and viability}

In Fig. 1A, results of Hoechst assay exhibited the influence of glucose concentration on hDPSC proliferation. DPSCs presented an increase in DNA quantity until 7 days and a decrease after. At 7 days, hDPSCs cultured with LG medium seemed to show higher DNA quantities (3.49 UI vs $2.31 \mathrm{UI})$ compared to those cultured in HG medium, but this difference was not significant 
$(p=0.70)$. Then, there was no significant difference $(p>0.05)$ after Hoechst assay between hDPSCs cultured in HG medium or LG medium.

MTT assay highlighted a progressive increase of cell metabolic activity until 21 days of culture

(Fig. 1B). Whatever the glucose concentration, no significant difference $(p>0.05)$ was observed in cell metabolic activity, whatever the kinetics point.

\subsection{Osteogenic differentiation under different glucose concentrations}

The osteogenic ability of hDPSCs was evaluated by the detection of mineralized bone nodules and expression of genes involved in bone development (COL1A1, RUNX2) and mineralization $(O C N)$

\subsubsection{Alizarin red staining}

After 28 days of culture, AR staining depicted the presence of precipitated calcium in hDPSCs cultured with osteogenic differentiation medium (Fig. 2A). Staining and then mineralization seemed visually more intense with HG medium than LG medium.

Mineralization quantitative assay highlighted that the increase of glucose concentration did not induce greater formation of precipitated calcium $(p=0.40)$ (Fig. 2B).

\subsubsection{Expression of osteogenic-related genes}

To investigate the influence of glucose concentration on hDPSC differentiation, we evaluated the modifications of gene expression of RUNX2 (early osteogenic marker), OCN (late osteogenic marker) and COL1Al at day 28 in HG group and LG group. No significative differences (RUNX2, $p=0.10 ; O C N, p=0.33 ; C O L 1 A 1, p=0.99)$ were observed in gene expression of these three genes between the two groups (Fig. 3). 


\section{Discussion}

Human mesenchymal stem cells play a major role in regenerative medicine and offer great promise in the field of bone tissue engineering. Among MSCs, DPSCs represent an interesting therapeutic option for mineralized tissue regeneration, and there has been a growing interest in their use over the last years (Batouli et al, 2003; Gronthos et al, 2002). Indeed, DPSCs are easily accessible and can differentiate into multiple lineages including osteoblasts (Cristaldi et al, 2018). It also has been demonstrated that DPSC potential in terms of proliferation and ability to induce mineralization is greater than BM-MSC potential (Alge et al, 2010). There is an imperative need for further research on DPSCs to better understand their cell function in order to improve their in vivo therapeutic use. A better understanding and modulation of some factors of DPSC local microenvironment such as glucose concentration could ameliorate cell proliferation and differentiation (Salazar-Noratto et al, 2020). Glucose concentration is a parameter that can easily be adjusted in vitro via the culture medium. Improving cell function and survival depending on glucose concentration seems particularly relevant, given the involvement of hyperglycemia in many pathologies, in which stem cell therapies could be helpful. In our study, we aimed to compare two glucose concentrations (5.5 mM and $20 \mathrm{mM})$ in terms of influence on DPSC proliferation, viability, and differentiation. We chose to focus on these glucose concentrations because they correspond to the routinely used culture medium. We chose one glucose concentration that corresponds to normal condition $(5.5 \mathrm{mM})$ and one considered as high $(20 \mathrm{mM})$, both in reference to in vivo serum glucose concentration and in vitro glucose concentration of cell culture medium. In fact, $5.5 \mathrm{mM}$ glucose concentration is usually considered as normal glucose serum condition and corresponds to LG culture medium in vitro. Glucose concentration of $20 \mathrm{mM}$ is considered in vitro as $\mathrm{HG}$ culture medium and is compared to hyperglycemic environment that can be found in vivo notably in diabetic patients (Kato et al, 2016). In the literature, several studies have investigated the influence of glucose 
on MSCs, but their results are divergent or inconsistent (Kanafi, Ramesh, Gupta \& Bhonde, 2013; Kato et al, 2016; Li et al, 2007; Lin et al, 2017; Seubbuk, Sritanaudomchai, Kasetsuwan \& Surarit, 2017; Stolzing, Coleman \& Scutt, 2006; Stolzing, Bauer \& Scutt, 2012; Wang et al, 2013; Wang, Wang, Lu \& Yu, 2019; Weil, Abarbanell, Herrmann, Wang \& Meldrum, 2009; Yamawaki, Taguchi, Komasa, Tanaka \& Umeda, 2017; Yang, Shen, Reece, Chen \& Yang, 2016; Zhang et al, 2017). To our knowledge, among those studies, only one work is available on DPSCs (Kanafi, Ramesh, Gupta \& Bhonde, 2013).

The present work first studied the influence of glucose in hDPSC proliferation and viability. We found no significant differences in terms of viability between hDPSCs cultured with LG medium and hDPSCs cultured with HG medium for 21 days. The proliferation rate was also similar between the two groups $(p>0.05)$. It seems to demonstrate that HG concentration in cell culture medium did not increase or had deleterious effect on the hDPSC proliferation and viability. Those results are consistent with a previous study on DPSCs that showed no significant difference at day 8 in terms of proliferation rate and cell viability depending on glucose concentration (Kanafi, Ramesh, Gupta \& Bhonde, 2013). In our work, proliferation rate has been measured until day 21 , but glucose effects seemed to be the same both on shortand long-term exposure. Similar results were obtained with BM-MSCs (Weil, Abarbanell, Herrmann, Wang \& Meldrum, 2009) in a work on glucose short-term exposure (2 days) with no significant difference depending on glucose concentration. Other studies on HG effects performed on other dental sources of MSCs displayed various results. Depending on studies, HG inhibited (Kato et al, 2016; Wang, Wang, Lu \& Yu, 2019) or promoted (Salazar-Noratto et al, 2019; Seubbuk, Sritanaudomchai, Kasetsuwan \& Surarit, 2017) proliferation of SCAPs (Wang, Wang, Lu, \& Yu, 2019), PDLSCs (Kato et al, 2016; Seubbuk, Sritanaudomchai, Kasetsuwan \& Surarit, 2017) or stem cells from human exfoliated deciduous teeth (SHEDs) (Kanafi, Ramesh, Gupta \& Bhonde, 2013). The same contradictory results were observed 
concerning BM-MSCs with either boosting (Deschepper et al, 2013; Elseberg et al, 2012; Kim, Heo \& Han, 2006; Li et al, 2007, Wang et al, 2013) or suppressing (Keats \& Khan, 2012; Stolzing, Bauer \& Scutt, 2012; Zhang et al, 2017) effect of HG on cell proliferation. These different outcomes could be explained by several factors such as the variation in delay between the cell seeding and the achievement of the proliferation assay (from 4 days to 4 weeks depending on studies (Deschepper et al, 2013; Elseberg et al, 2012; Kanafi, Ramesh, Gupta \& Bhonde, 2013; Kato et al, 2016; Kim, Heo \& Han, 2006; Keats \& Khan, 2012; Li et al, 2007; Stolzing, Bauer \& Scutt, 2012; Seubbuk, Sritanaudomchai, Kasetsuwan \& Surarit, 2017; Wang et al, 2013; Wang, Wang, Lu \& Yu, 2019; Zhang et al, 2017), variation of cell seeding densities, the individual donors' variable trends ( $\mathrm{Li}$ et al, 2007) or the differences between types of stem cells.

The second part of our work focused on the effects of glucose concentration on osteogenic differentiation and mineralization of human DPSCs. Studies demonstrated that hDPSCs can differentiate into osteoblast lineage in the presence of osteoinductive agents (Papaccio et al, 2006). The osteogenic differentiation of stem cells is regulated by specific molecules and factors of the microenvironment. Among these, the role of glucose on osteogenesis was mainly studied on BM-MSCs, and the results in the literature are confusing. Therefore, some studies have shown that HG culture medium enhanced the osteogenic differentiation of BM-MSCs (Li et al, 2007; Yamawaki, Taguchi, Komasa, Tanaka \& Umeda, 2017), PDLSCs (Seubbuk, Sritanaudomchai, Kasetsuwan \& Surarit, 2017) or SCAPs (Wang, Wang, Lu \& Yu, 2019). In contrast, some other studies demonstrated that HG concentration suppressed or reduced BMMSC (Stolzing, Bauer \& Scutt, 2012; Wang et al, 2013) or PDLSC (Kato et al, 2016) osteoblastic differentiation. To our knowledge, no study compared the effects of LG and HG medium on osteogenic differentiation of DPSCs. One study obtained similar osteogenic differentiation of SHEDs or DPSCs in presence of hypoxia or HG (qualitative Von Kossa 
staining) (Kanafi, Ramesh, Gupta \& Bhonde, 2013). However, the osteogenic differentiation potential of DPSCs was not compared between HG and LG.

In our work, the mineralization assay by alizarin red staining on DPSCs after 28 days of culture showed no significant difference $(p>0.05)$ between cells cultured with HG osteoinductive medium $(20 \mathrm{mM})$ or LG osteoinductive medium $(5.5 \mathrm{mM})$. We obtained for both groups mineralized nodules, and even if the staining visually seemed stronger with the HG medium, the quantitative assay did not indicate significant difference $(p>0.05)$ between the two groups. Then, we reviewed how glucose concentration could influence the expression of several osteoblastic-related genes: RUNX2, $O C N$ and COL1A1. RUNX2 is a transcription factor which is essential in the early stages of DPSC osteogenic differentiation (Yu et al, 2007). OCN is a later-stage marker of mineralized bones (Bai et al, 2010). COL1A1 is a gene whose expression is closely correlated with the osteoblast proliferation stage (Nakashima \& de Crombrugghe, 2003). Our results showed no significative difference $(p>0.05)$ between osteoblastic-related gene expression for hDPSCs induced with LG osteogenic medium and induced with HG osteogenic medium after 28 days of differentiation. These results confirmed previous results obtained with mineralization assay. Then, HG concentration appears to have no boosting or suppressive effect on hDPSC osteogenic-related gene expression.

To conclude, our work has not established evidence of neither boosting nor deleterious impact of high glucose on hDPSC behavior. hDPSCs cultured in HG medium did not exhibit a higher proliferation rate, viability or osteogenic differentiation compared with those cultured with LG medium. Despite the lack of numerous studies in the existing literature about the effects of glucose concentration on DPSCs, especially about DPSC osteogenic differentiation, we can formulate the following assumptions. First, the different type of stem cells used in the experiments could explain the different results. Secondly, cells were exposed to osteoinductive 
medium for different culture times. Thus, in our work, stem cells were cultured for 28 days in presence of osteoinductive media vs. 7 (Kanafi, Ramesh, Gupta \& Bhonde,, 2013), 14 (Stolzing, Bauer \& Scutt, 2012) or 21 days in other studies (Kato et al, 2016; Wang et al, 2013). Finally, Li et al. (2007) have performed only qualitative alizarin red staining after 28 days of BM-MSC culture with HG or LG osteoinductive medium.

Further investigations are required for a better understanding of the molecular mechanisms of glucose on DPSCs. Nevertheless, this finding seems to highlight an interesting resistance of hDPSCs against high glucose concentration and could be promising in bone tissue engineering in pathological conditions such as diabetes mellitus. 


\section{Funding}

This research did not receive any specific grant from funding agencies in the public, commercial, or not-for-profit sectors.

\section{Declaration of competing interest}

The authors declare that they have no conflict of interest.

\section{Acknowledgments}

This research was supported by CHRU Nancy (Direction de la Recherche et de l'Innovation). We thank Doctor Ndeye Coumba NDIAYE (Epidemiologist/Biostatistician) for her guidance and validation in the statistical analysis of data. 


\section{References}

Alge, D. L., Zhou, D., Adams, L. L., Wyss, B. K., Shadday, M. D., Woods, E. J., ...Goebel, W. S. (2010). Donor-matched comparison of dental pulp stem cells and bone marrowderived mesenchymal stem cells in a rat model. Journal of Tissue Engineering and Regenerative Medicine, 4(1), 73-81. https://doi.org/10.1002/term.220.

Bai, Y., Bai, Y., Matsuzaka, K., Hashimoto, S., Kokubu, E., Wang, X., \& Inoue, T. (2010). Formation of bone-like tissue by dental follicle cells co-cultured with dental papilla cells. Cell and Tissue Research, 342(2), 221-231. https://doi.org/10.1007/s00441-010-1046-9.

Batouli, S., Miura, M., Brahim, J., Tsutsui, T. W., Fisher, L. W., Gronthos, S., ...Shi, S. (2003). Comparison of stem-cell-mediated osteogenesis and dentinogenesis. Journal of Dental Research, 82(12), 976-981. https://doi.org/10.1177/154405910308201208.

Cha, Y., Jeon, M., Lee, H. S., Kim, S., Kim, S. O., Lee, J. H., \& Song, J. S. (2015). Effects of in vitro osteogenic induction on in vivo tissue regeneration by dental pulp and periodontal ligament stem cells. Journal of Endodontics, 41(9), 1462-1468. https://doi.org/10.1016/j.joen.2015.04.010.

Chamieh, F., Collignon, A. M., Coyac, B. R., Lesieur, J., Ribes, S., Sadoine, J., ...Rochefort, G. Y. (2016). Accelerated craniofacial bone regeneration through dense collagen gel scaffolds seeded with dental pulp stem cells. Scientific Reports, 6, 38814. https://doi.org/10.1038/srep38814.

Cristaldi, M., Mauceri, R., Tomasello, L., Pizzo, G., Pizzolanti, G., Giordano, C., \& Campisi, G. (2018). Dental pulp stem cells for bone tissue engineering: a review of the current literature and a look to the future. Regenerative Medicine, 13, 207-218. https://doi.org/10.2217/rme-2017-0112. 
Deschepper, M., Manassero, M., Oudina, K., Paquet, J., Monfoulet, L. E., Bensidhoum, M., ...Petite, H. (2013). Proangiogenic and prosurvival functions of glucose in human mesenchymal stem cells upon transplantation. Stem Cells, 31(3), 526-535. https://doi.org/10.1002/stem.1299.

Ducret, M., Fabre, H., Degoul, O., Atzeni, G., McGuckin, C., Forraz, N., ...Farges, J. C. (2015). Manufacturing of dental pulp cell-based products from human third molars: current strategies and future investigations. Frontiers in Physiology, 6, 213. https://doi.org/10.3389/fphys.2015.00213.

Elseberg, C. L., Leber, J., Salzig, D., Wallrapp, C., Kassem, M., Kraume, M., \& Czermak, P. (2012). Microcarrier-based expansion process for hMSCs with high vitality and undifferentiated characteristics. The International Journal of Artificial Organs, 35(2), 93107. https://doi.org/10.5301/ijao.5000077.

Giuliani, A., Manescu, A., Langer, M., Rustichelli, F., Desiderio, V., Paino, F., ...Papaccio, G. (2013). Three years after transplants in human mandibles, histological and in-line holotomography revealed that stem cells regenerated a compact rather than a spongy bone: biological and clinical implications. Stem Cells Translational Medicine, 2(4), 316-324. https://doi.org/10.5966/sctm.2012-0136.

Gregory, C. A., Gunn, W. G., Peister, A., \& Prockop, D. J. (2004). An Alizarin red-based assay of mineralization by adherent cells in culture: comparison with the cetylpyridinium $\begin{array}{llll}\text { chloride } \quad \text { extraction. } & \text { Analytical } & \text { Biochemistry, } & 329(1),\end{array}$ https://doi.org/10.1016/j.ab.2004.02.002.

Gronthos, S., Mankani, M., Brahim, J., Robey, P. G., \& Shi, S. (2000). Postnatal human dental pulp stem cells (DPSCs) in vitro and in vivo. Proceedings of the National Academy of Sciences of the United States of America, 97(25), 13625-13630. https://doi.org/10.1073/pnas.24030979. 
Gronthos, S., Brahim, J., Li, W., Fisher, L. W., Cherman, N., Boyde, A., ...Shi, S. (2002). Stem cell properties of human dental pulp stem cells. Journal of Dental Research, 81(8), 531-535. https://doi.org/10.1177/154405910208100806.

Hilkens, P., Gervois, P., Fanton, Y., Vanormelingen, J., Martens, W., Struys, T., ...Bronckaers, A. (2013). Effects of isolation methodology on stem cells properties and multilineage differentiation potential in human dental pulp stem cells. Cell and Tissue Research, 353(1), 65-78. https://doi.org/10.1007/s00441-013-1630-x.

Jiao, H., Xiao, E., \& Graves, D. T. (2015). Diabetes and its effects on bone and fracture healing. Current Osteoporosis Reports, 13(5), 327-335. https://doi.org/ 10.1007/s11914015-0286-8.

Kalaitzoglou, E., Popescu, I., Bunn, R. C., Fowlkes, J. L \& Thrailkill, K. M. (2016). Effects of type 1 diabetes on osteoblasts, osteocytes and osteoclasts. Current Osteoporosis Reports, 14 (6), 310-319. https://doi.org/10.10007/s11914-016-0329-9.

Kanafi, M. M., Ramesh, A., Gupta, P. K., \& Bhonde, R. R. (2013). Influence of hypoxia, high glucose, and low serum on growth kinetics of mesenchymal stem cells from deciduous and permanent teeth. Cells Tissues Organs, 198(3), 198-208. https://doi.org/10.1159/000354901.

Kato, H., Taguchi, Y., Tominaga, K., Kimura, D., Yamawaki, I., Noguchi, ...Umeda, M. (2016). High glucose concentrations suppress the proliferation of human periodontal ligament stem cells and their differentiation into osteoblasts. Journal of Periodontology, 87(4), 44-51. https://doi.org/10.1902/jop.2015.150474.

Keats, E., \& Khan, Z.A. (2012). Unique responses of stem cell-derived vascular endothelial and mesenchymal cells to high levels of glucose. PloS One, 7(6), 38752. https://doi.org/10.1371/journal.pone.0038752. 
Kichenbrand, C., Velot, E., Menu, P., \& Moby, V. (2019). Dental Pulp stem cell-derived conditioned medium: an attractive alternative for regenerative therapy. Tissue Engineering Part B: Reviews, 25(1), 78-88. https://doi.org/10.1089/ten.teb2018.0168.

Kim, Y. H., Heo, J. S., \& Han, H. J. (2006). High glucose increases cell cycle regulatory proteins level of mouse embryonic stem cells via PI3-K/Akt and MAPKs signal pathways. Journal of Cellular Physiology, 209(1), 94-102. https://doi.org/10.1002/jcp.20706.

Laino, G., Graziano, A., d’Aquino, R., Pirozzi, G., Lanza, V., Valiante, S., ...Papaccio, G. $\left(2006^{\mathrm{a}}\right)$. An approachable human adult stem cell source for hard-tissue engineering. Journal of Cellular Physiology, 206(3), 693-701. https://doi.org/10.1002/jcp.20526.

Laino, G., Carinci, F., Graziano, A., d'Aquino, R., Lanza, V., De Rosa, A., ...Papaccio, G. $\left(2006^{\mathrm{b}}\right)$. In vitro bone production using stem cells derived from human dental pulp. Journal of Craniofacial Surgery, 17(3), 511-515. https://doi.org/10.1097/00001665-200605500000021.

Le Blanc, K. \& Pittenger, M. (2005). Mesenchymal stem cells: progress toward promise. Cytotherapy, 7(1), 36-45. https://doi.org/10.1080/14653240510018118.

Li, Y. M., Schilling, T., Benish, P., Zeck, S., Meissner-Weigl, J., Schneider, D., ... Ebert, R. (2007). Effects of high glucose on mesenchymal stem cell proliferation and differentiation. Biochemichal and Biophysical Research Communications, 363(1), 209-215. https://doi.org/10.1016/j.bbrc.2007.08.161.

Liang, C., Li, H., Tao, Y., Zhou, X., Li, F., Chen, G., \& Chen, Q. (2012). Responses of human adipose-derived mesenchymal stem cells to chemical microenvironment of the intervertebral disc. Journal of Translational Medicine, 10, 49. https://doi.org/10.1186/1479-5876-10-49.

Lin, Y. C., Li, Y. J., Rui, Y. F., Dai, G. C., Shi, L., Xu, H. L., ...Teng, G. J. (2017). The effects of high glucose on tendon-derived stem cells: implications of the pathogenesis of 
diabetic tendon disorders. Oncotarget, $8(11), \quad 17518-17528$. https://doi.org/10.18632/oncotarget.15418.

Ling, L. E., Feng, L., Liu, H. C., Wang, D. S., Shi, Z. P., Wang, J. C., ...\& Lv, Y. (2015). The effects of calcium phosphate composite scaffolds on the osteogenic differentiation of rabbit dental pulp stem cells. Journal of Biomedical Materials Research Part A, 103(5), 1732-1745. https://doi.org/10.1002/jbm.a.35303.

Nakashima, K., \& de Crombrugghe, B. (2003). Transcriptional mechanisms in osteoblast differentiation and bone formation. Trends in Genetics, 19(8), 458-466. https://doi.org/10.1016/S0168-9525(03)00176-8.

Neuss, S., Stainforth, R., Salber, J., Schenck, P., Bovi, M., Knüchel, R., \& Perez-Bouza, A. (2008). Long- term survival and bipotent terminal differentiation of human mesenchymal stem cells (hMSC) in combination with a commercially available three-dimensional

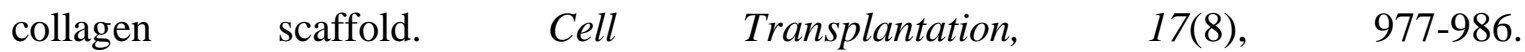
https://doi.org/10.3727/096368908786576462.

Papaccio, G., Graziano, A., d'Aquino, R., Graziano, M. F., Pirozzi, G., Menditti, D., ...Laino, G. (2006). Long-term cryopreservation of dental pulp stem cells (SBP-DPSCs) and their differentiated osteoblasts: a cell source for tissue repair. Journal of Cellular Physiology, 208(2), 319-325. https://doi.org/10.1002/jcp.20667.

Polymeri, A., Giannobile, W. V., \& Kaigler, D. (2016). Bone marrow stromal stem cells in tissue engineering and regenerative medicine. Hormone and Metabolic Research, 48(11), 700-713. https://doi.org/10.1055/S-0042-118458.

Quarto, R., Mastrogiacomo, M., Cancedda, R., Kutepov, S.M., Mukhachev, V., Lavroukov, ...Marcacci, M. (2001). Repair of large bone defects with the use of autologous bone marrow stromal cells. New England Journal of Medicine, 344(5), 385-386. https://doi.org/10.1056/NEJM200102013440516. 
Salazar-Noratto, G. E., Luo, G., Denoeud, C., Padrona, M., Moya, A., Bensidhoum, M., ...Petite, E. (2020). Concise Review: Understanding and leveraging cell metabolism to enhance mesenchymal stem cell transplantation survival in tissue engineering and regenerative medicine applications. Stem Cells, 38(1), 22-33. https://doi.org/10.1002/stem.3079.

Saki, N., Jalalifar, M. A., Soleimani, M., Hajizamani, S., \& Rahim, F. (2013). Adverse effect of high glucose concentration on stem cell therapy. International Journal of Hematology- Oncology Stem Cell Research, 7(3), 34-40.

Seubbuk, S., Sritanaudomchai, H., Kasetsuwan, J., \& Surarit, R. (2017). High glucose promotes the osteogenic differentiation capability of human periodontal ligament fibroblasts. Molecular Medicine Reports, 15(5), 2788-2794. https://doi.org/10.3892/mmr.2017.6333.

Stanford, C. M., Jacobson, P. A., Eanes, E. D., Lembke, L. A., \& Midura, R. J. (1995). Rapidly forming apatitic mineral in an osteoblastic cell line (UMR 106-01 BSP). Journal of Biological Chemistry, 270(16), 9420-9428. https://doi.org/10.1074/jbc.270.16.9420.

Stolzing, A., Coleman, N., \& Scutt, A. (2006). Glucose-induced replicative senescence in mesenchymal stem cells. Rejuvenation Research, 9(1), 31-35. https://doi.org/10.1089/rej.2006.9.31.

Stolzing, A., Bauer, E., \& Scutt, A. (2012). Suspension cultures of bone marrow derived mesenchymal stem cells: effects of donor age and glucose level. Stem Cells and Development, 21(14), 2718-2723. https://doi.org/10.1089/scd.2011.0406.

Wang, J., Wang, B., Li, Y., Wang, D., Lingling, E., Bai, Y., \& Liu, H. (2013). High glucose inhibits osteogenic differentiation through the BMP signaling pathway in bone mesenchymal stem cells in mice. EXCLI Journal, 12, 584-597. https://doi.org/10.17877/DE290R-7335. 
Wang, Y., Wang, Y., Lu, Y., \& Yu, J. (2019). High glucose enhances the odonto/osteogenic differentiation of stem cells from apical papilla via NF-KappaB signaling pathway. BioMed Research International, 2019, 5068258. https://doi.org/10.1155/2019/5068258.

Weil, B. R., Abarbanell, A. M., Herrmann, J. L., Wang, Y., \& Meldrum, D. R. (2009). High glucose concentration in cell culture does not acutely affect human mesenchymal stem cell growth factor production or proliferation. American Journal of Physiology-Regulatory, Integrative and Comparative Physiology, 296(6), R1735-1743. https://doi.org/10.1152/ajpregu.90876.2008.

Wexler, S. A., Donaldson, C., Denning-Kendall, P., Rice, C., Bradley, B., \& Hows, J. M. (2003). Adult bone marrow is a rich source of human mesenchymal 'stem' cells but umbilical cord and mobilized adult blood are not. British Journal of Haematology, 121(2), 368-374. https://doi.org/10.1055/s-0042-118458.

Wongsupa, N., Nuntanaranont, T., Kamolmattayakul, S., \& Thuaksuban, N. (2017). Assessment of bone regeneration of a tissue-engineered bone complex using human dental pulp stem cells/poly(e-caprolactone)-biphasic calcium phosphate scaffold constructs in rabbit calvarial defects. Journal of Materials Science Materials in Medicine, 28(5), 77. https://doi.org/10.1007/s10856-017-5883-X.

Yamawaki, I., Taguchi, Y., Komasa, S., Tanaka, A., \& Umeda, M. (2017). Effects of glucose concentration on osteogenic differentiation of type II diabetes mellitus rat bone marrow-derived mesenchymal stromal cells on a nano-scale modified titanium. Journal of Periodontal Research, 52(4), 761-771. https://doi.org/10.1111/jre.12446.

Yang, P., Shen, W. B., Reece, E. A., Chen, X., \& Yang, P. (2016). High glucose suppressed embryonic stem cells differentiation into neural lineage cells. Biochemical and Biophysical Research Communication, 472(2), 306-312. https://doi.org/10.1016/j.bbrc.2016.02.117. 
Yu, J., Wang, Y., Deng, Z., Tang, L., Li, Y., Shi, J., \& Jin, Y. (2007). Odontogenic capability: bone marrow stromal stem cells versus dental pulp stem cells. Biology of the Cell, 99(8), 465-474. https://doi.org/10.1042/BC20070013.

Zhang, W., Walboomers, X. F., Shi, S., Fan, M., \& Jansen, J. A. (2006). Multilineage differentiation potential of stem cells derived from human dental pulp after cryopreservation. Tissue $\quad$ Engineering, 2813-2823. https://doi.org/10.1089/ten.2006.12.2813.

Zhang, Z. Y., Teoh, S. H., Chong, M. S., Schantz, J. T., Fisk, N. M., Choolani, M. A., \& Chan, J. (2009). Superior osteogenic capacity for bone tissue engineering of fetal compared with perinatal and adult mesenchymal stem cells. Stem Cells, 27(1), 126-137. https://doi.org/10.1634/stemcells.2008-0456.

Zhang, D., Lu, H., Chen, Z., Wang, Y., Lin, J., Xu, S., ...Pan, J. (2017). High glucose induces the aging of mesenchymal stem cells via Akt/mTOR signaling. Molecular Medicine Reports, 16(2), 1685-1690. https://doi.org/10.3892/mmr.2017.6832. 


\section{Figure captions}

Fig. 1. Effect of different concentrations of glucose (low $(5.5 \mathrm{mM})$ or high $(20 \mathrm{mM})$ glucose concentration) on hDPSC proliferation and metabolic activity. DPSCs were cultured for 21 days. A. hDPSC DNA quantification $(\mu \mathrm{g} / \mu \mathrm{L})$, B. Measurement of MTT absorbance at $540 \mathrm{~nm}$ and normalized by DNA absorbance. Results are mean $\pm S E(n=3)$.

Fig. 2. Effect of glucose concentration on the formation of mineralized bone nodules. A. Alizarin red staining of hDPSC cultured for 28 days in basal medium (A.1.), low glucose (LG, $5.5 \mathrm{mM}$ ) osteogenic induction medium (A.2.) and high glucose (HG, $20 \mathrm{mM}$ ) osteogenic induction medium (A.3.). B. Quantification of alizarin red staining for hDPSC cultured for 28 days in LG- or HG-medium supplemented (LGD and HGD) or not (control, basal medium) with osteogenic factors, $a$ : $\mathrm{p}<0.05$ versus basal medium. Results are medians $(\mathrm{n}=3)$.

Fig. 3. Effect of glucose concentration on osteogenic gene expression in hDPSC. The expression of RUNX2, OCN and COL1A1 genes in hDPSC was measured using real-time PCR. There was no significative difference $(\mathrm{p}>0.05)$ at day 28 between low glucose $(5.5 \mathrm{mM}) v s$ high glucose (20 mM) groups in RUNX2, OCN, and COL1A1 expression in DPSCs. Results are mean $\pm \operatorname{SE}(\mathrm{n}=3)$ 
Table 1. Primers used for reverse transcription-quantitative polymerase chain reaction analysis

\begin{tabular}{|l|l|c|}
\hline Genes & Primers & Sequences (5'-3') \\
\hline RUNX2 & Forward & CCCGTGGCCTTCAAGGT \\
& Reverse & CGTTACCCGCCATGACAGTA \\
\hline OCN & Forward & GTGCAGAGTCCAGCAAAGGT \\
& Reverse & TCAGCCAACTCGTCACAGTC \\
\hline COL1A1 & Forward & AGGTGCTGATGGCTCTCCT \\
& Reverse & GGACCACTTTCACCCTTGT \\
\hline$R P 29$ & Forward & AGATGGGTCACCAGCAGCTGTACTG \\
& Reverse & AGACACGACAAGAGCGAGAA \\
\hline
\end{tabular}


A

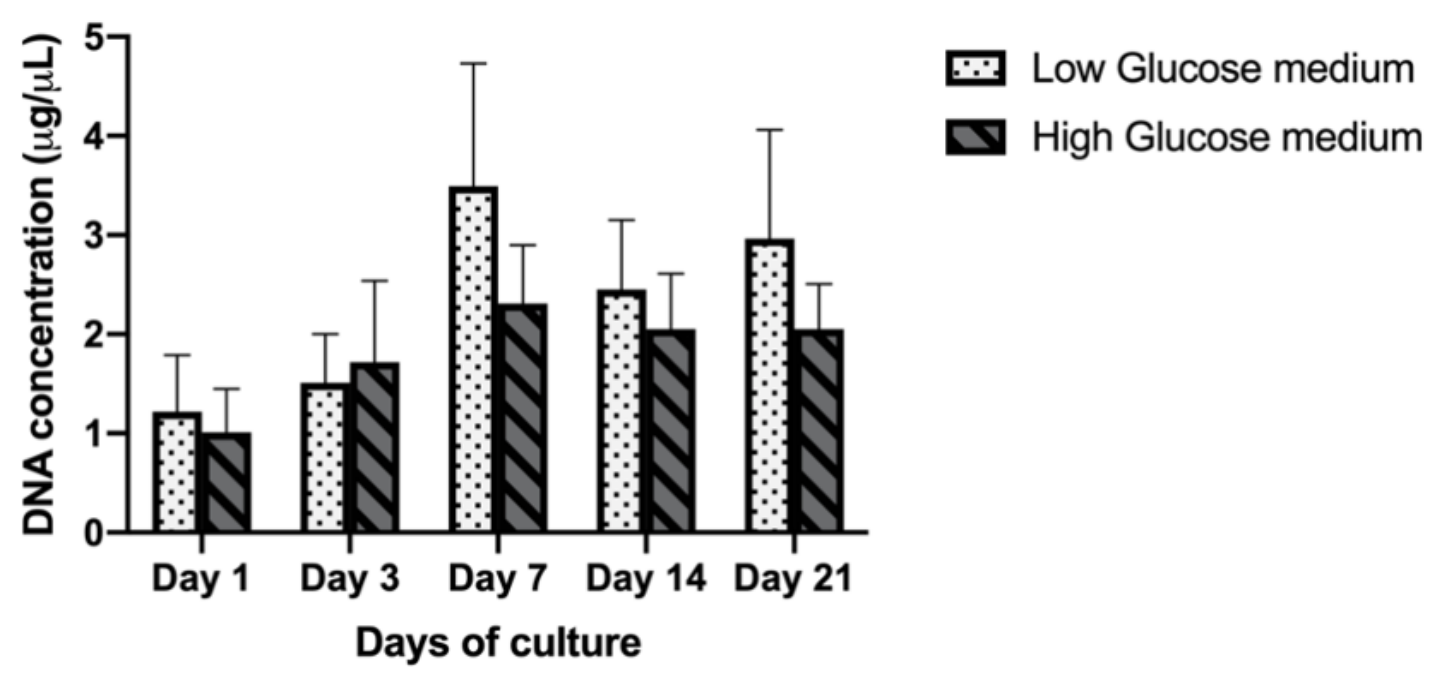

B

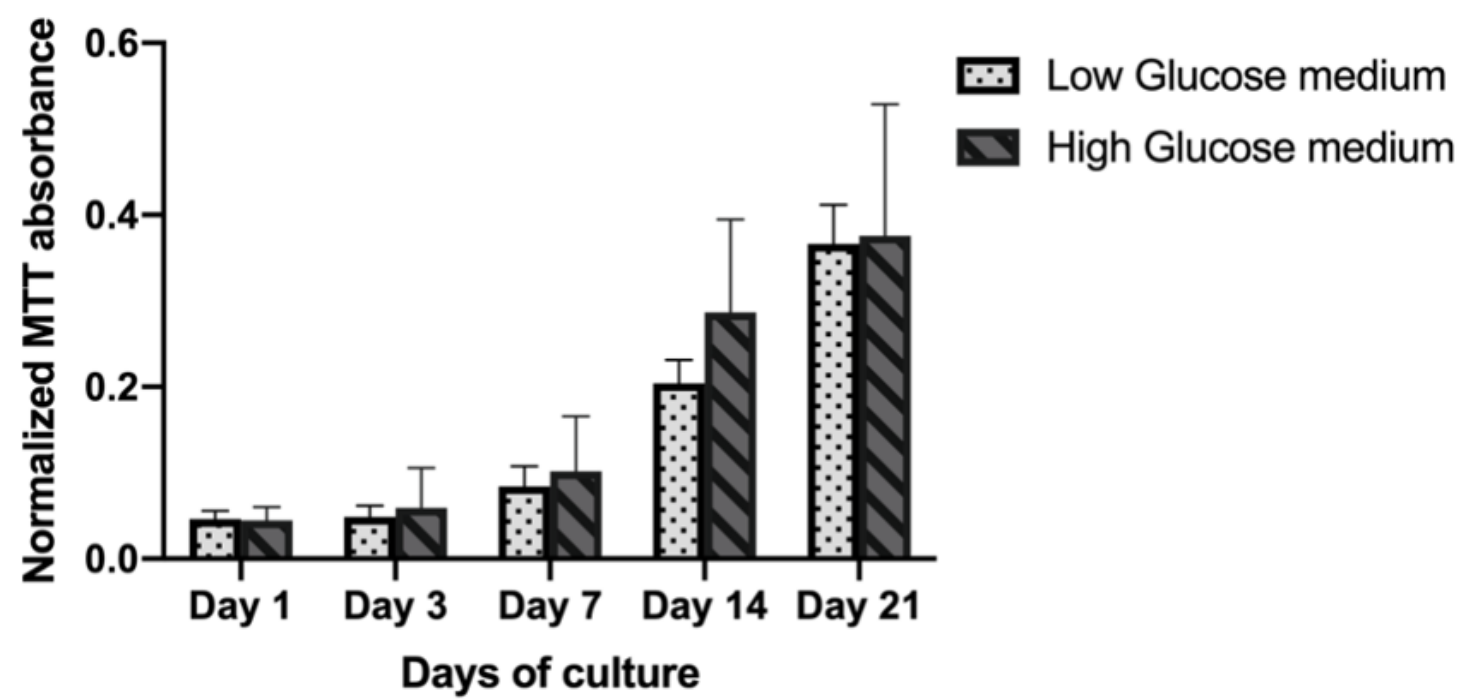

Figure 1 
A.

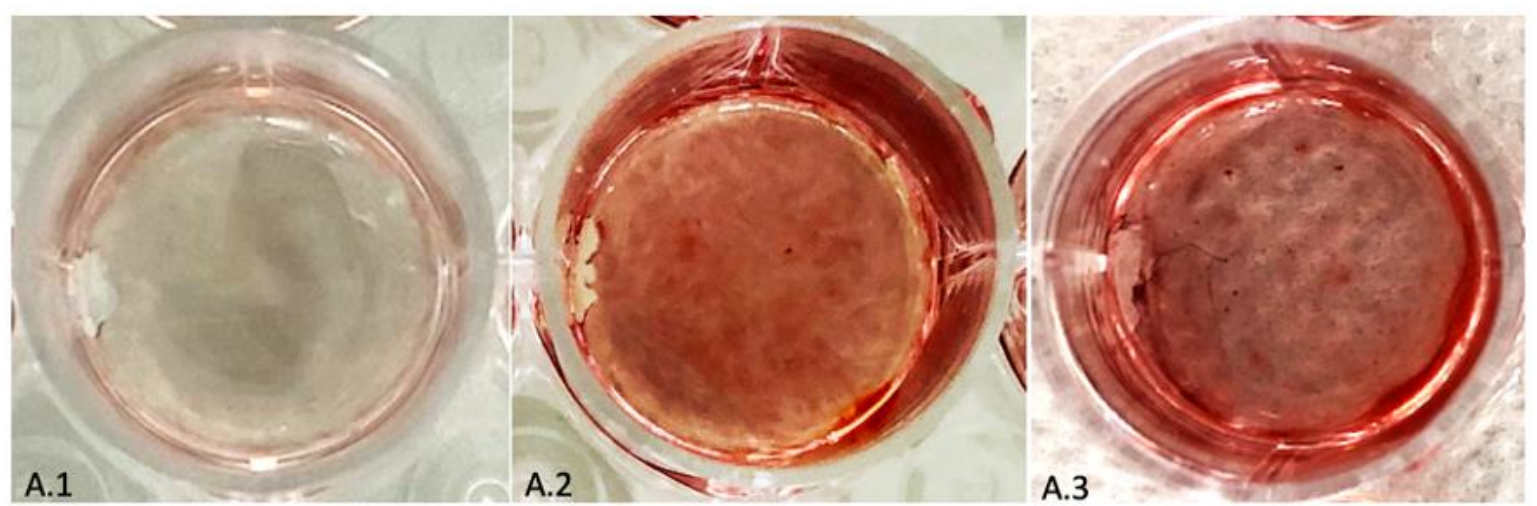

B.

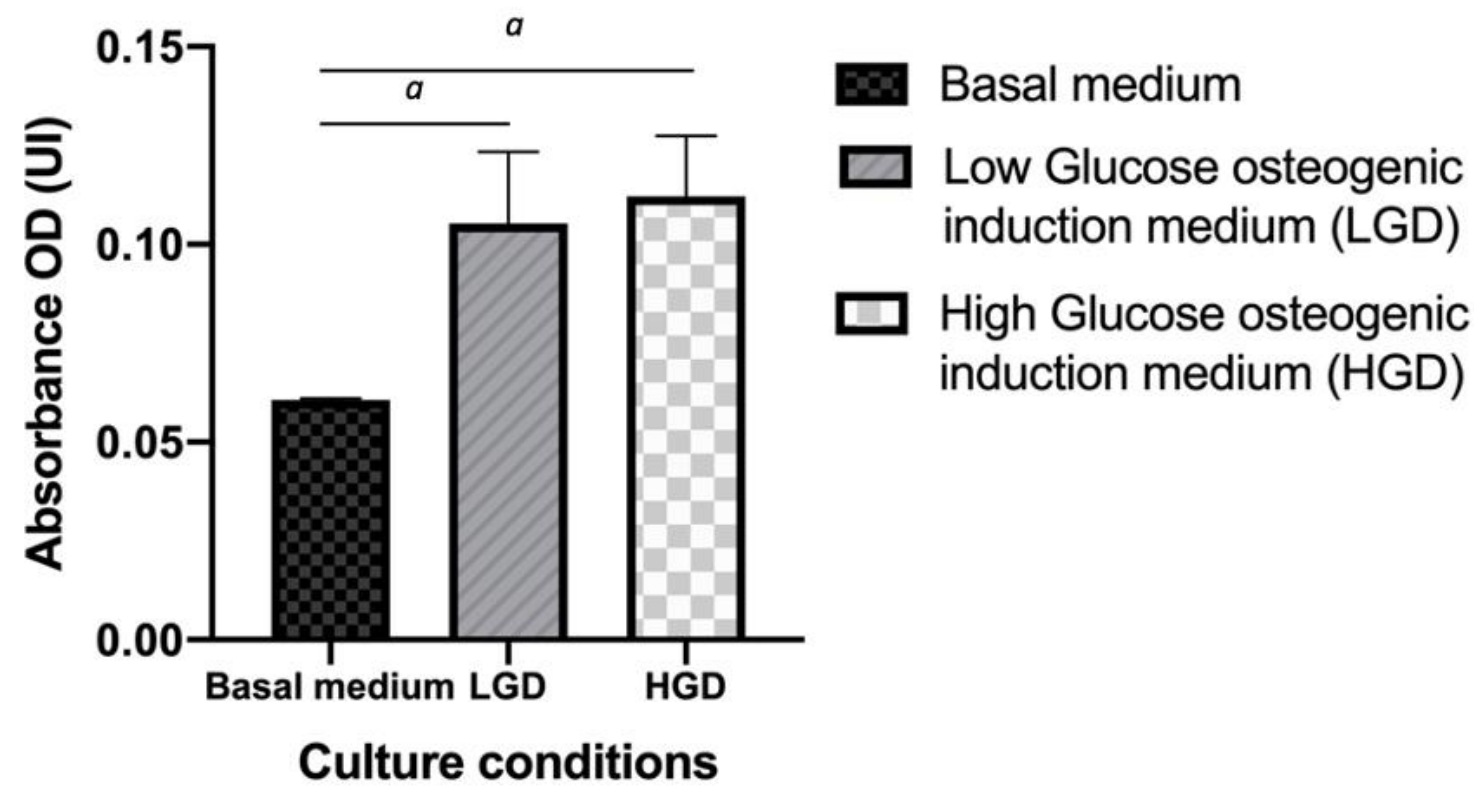

Figure 2 


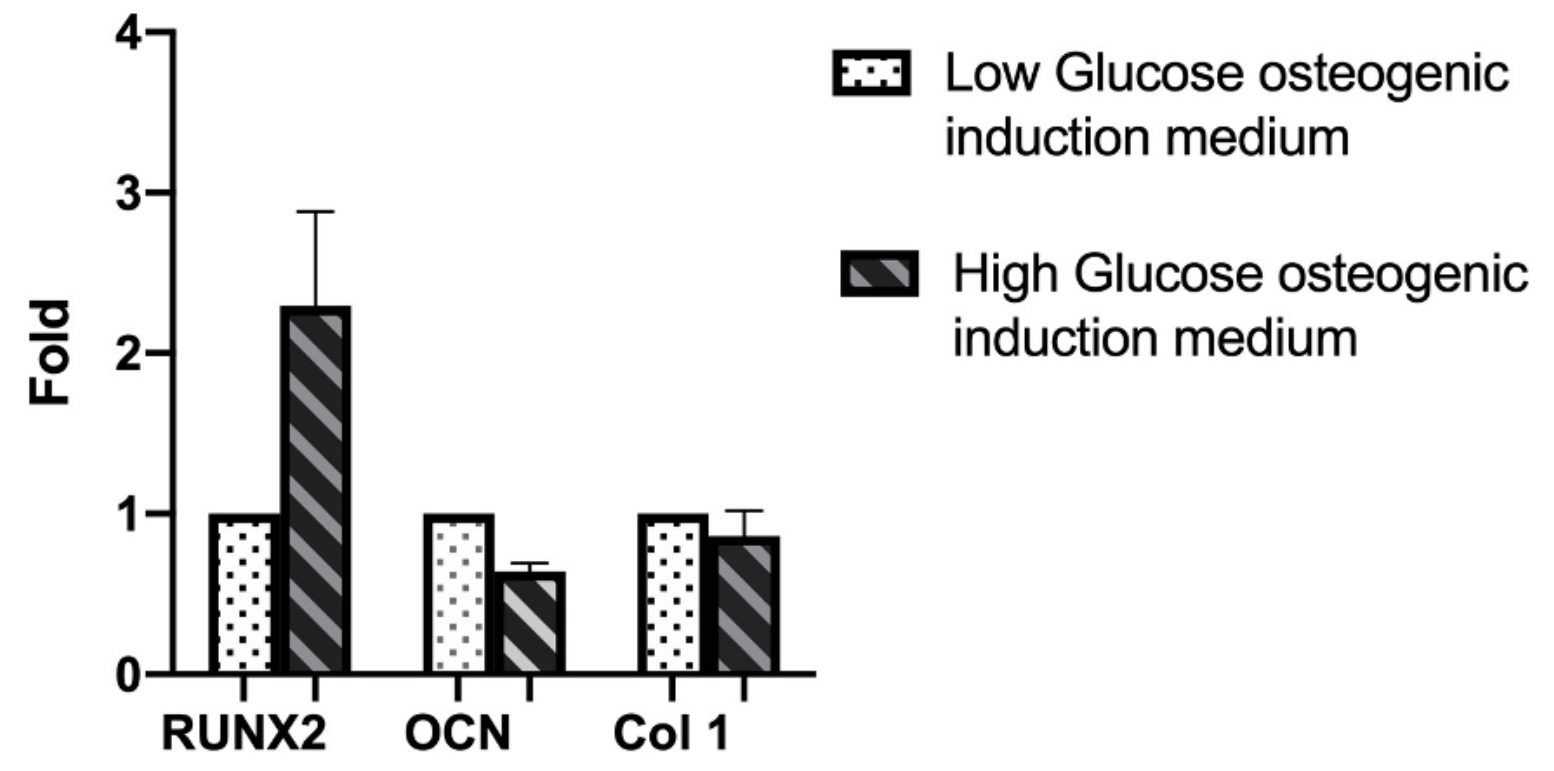

Figure 3 